\title{
Prediction of flow length in injection molding for engineering plastics by fuzzy logic under different processing conditions
}

\author{
Aydin Salimi • Mehmet Subaşı $\cdot$ Lezgi Buldu • \\ Çetin Karataş
}

Received: 17 May 2012/Accepted: 2 October 2012/Published online: 7 November 2012

(c) The Author(s) 2012. This article is published with open access at Springerlink.com

\begin{abstract}
Flow length determination is one of the most important tasks in injection mold design. In order to achieve the perfect filling of the mold, proper designs for the channel depth and other injection parameters (such as melt temperature, injection pressure and etc.) should be conducted. In this research, melt temperature and injection pressure were considered as input parameters to investigate the flow length, in the most commonly used plastics including acrylonitrile butadiene styrene (ABS), polycarbonate (PC), polyamide 6.6 (PA 6.6), polyoxymethylene (POM). This study was carried out, based on various channel depths, according to ASTM D 3123. A new method based on a fuzzy logic method was developed to predict the amount of flow length in relation to the input parameters such as pressure, channel depth, and temperature. When the present method is used, the problem of finding the optimum mold design can be solved faster compared to the traditional modeling programs. The largest estimated amounts of flow lengths by the fuzzy logic model were 1215, 596, 963 and $1040 \mathrm{~mm}$ for POM, PC, PA 6.6 and ABS, respectively. The maximum measured values were 1235, 579, 948 and $1050 \mathrm{~mm}$ for the same material. Experimental tests have been conducted to justify the
\end{abstract}

\footnotetext{
A. Salimi $(\bowtie)$

Department of Mechanical Engineering, Faculty of Engineering, University of Payame Noor, Tehran, Iran

e-mail: aydin952@gmail.com

M. Subaş1

Ataturk Vocational School of Higher Education, Gazi

University, Teknikokullar, 06500 Ankara, Turkey

L. Buldu · Ç. Karataş

Department of Mechanical Technology, Faculty of Technology,

Gazi University, Teknikokullar, 06500 Ankara, Turkey
}

accuracy of the developed method. It was confirmed by regression analysis that the amount of $R^{2}$ for the measured and estimated values was 0.920529 . The results of this research show that the fuzzy logic system is a reliable method to predict the short shots in an injection process.

Keywords Flow length · Injection molding · Fuzzy logic · Engineering plastics $\cdot$ Prediction

\section{Introduction}

Plastics industry is one among the fast growing industries in recent few decades. Application of plastics is growing due to their advantages in terms of specific properties and less production costs [1-3]. Plastics have a wide variety of applications. Each application demands specific chemical and physical properties. Commercial plastics can only provide a limited variety of chemical and physical properties. Usually some operations are conducted on commercial plastics to obtain new materials that can meet the required chemical and physical specifications. These new materials are usually referred as engineering plastics. Advancements of engineering plastics promise higher quality products with better performances; therefore, the application of engineering plastics in different industries such as aero-space, electronics, and automobile industries is increasing continuously [4-6].

Injection molding is a rapid and versatile manufacturing technique which is used in the plastics industry to produce objects with different sizes, shapes and, if needed, many details [7]. Since an injection mold is usually the most important and expensive assembly to produce plastic parts, the designing of suitable molds is an active research area. The moldability and the flow length ratio are two important 
considerations in the design of injection molds that are studied in this research $[8,9]$.

The study of flow length is usually carried out based on some experiments. The experiments are conducted using spiral molds appropriate to ISO standards (ASTM D 3123 (2009) standard test method for spiral flow of low-pressure thermosetting molding compounds 1-4). In earlier research attempt, it has been shown that the spiral depth affects the flow length [10]. It has been found that by increasing the value of spiral channel height, mold temperature and injection pressure, the flow length, based on the type of materials, increases as well. In this research, the experimental materials were molded based on ASTM D 3123 specifications. This standard introduces the specifications for spiral flow length and the ratio of viscosity and flow of the plastics (ASTM D 3123). The flow lengths in spiral tests were measured experimentally and compared to the corresponding values provided in the above standard.

This study covers two main objectives: (1) analyzing the moldability of engineering plastics including acrylonitrile butadiene styrene (ABS), polycarbonate (PC), polyamide 6.6 (PA 6.6), polyoxymethylene (POM), and investigating their flow lengths based on the injection parameters (melt temperature, injection pressure and flow rate) on the plastics melts. As a result of the experiment, the PA6.6 and POM materials have shown much greater flow lengths. Moreover, the maximum measured values of the flow length of the engineering plastics including PA 6.6, POM, $\mathrm{PC}$ and $\mathrm{ABS}$ were obtained as 948, 1235, 579 and $1050 \mathrm{~mm}$ during the experiments, in the order given; (2) predicting and obtaining the amounts of flow lengths in various plastics. For this purpose, a fuzzy logic model was designed and developed based on different injection parameters and channel depths. This method is cost effective and a reliable way to predict the flow lengths prior the injection molding process.

\section{Experimental analysis}

In this paper, four engineering plastics namely acrylonitrile butadiene styrene (ABS), polycarbonate (PC), polyamide 6.6 (PA 6.6), polyoxymethylene (POM) were selected as sample materials. The injection parameters of the above materials and their physical properties are listed in Table 1 .

Materials were molded using a JINHWA (Çalışkan Plastic Ltd. Sti., Turkey) type plastic injection machine with a maximum injection pressure of 1400 bar and shot weight capacity of $160 \mathrm{~g}$.

A mold containing spiral chutes was used for molding the plastics. This mold was designed and produced according to ASTM D 3123 standards. Figure 1 shows the schematic diagram of the mold. Beside the $1.6 \mathrm{~mm}$ of channel depth, the mold has been made for three other channels with 2, 3 and $4 \mathrm{~mm}$ depths.

\section{Test procedure}

In this research, to investigate the effects of injection parameters on flow length, four different commercial plastics were molded in a mold containing spiral chutes. The mold was mounted on a plastic injection machine and the effects of melt temperature, channel depth, injection pressure on these plastics and their flow lengths were measured.

During the experiments, the injection pressure was maintained constant and the melt temperature varied according to the given data in Table 1. Before feeding the raw material into the extruder, the materials were dehumidified based on the recommendations of the companies (Table 1). Before starting the tests, the hoses were attached to the water ducts in the mold to lead oil and sufficiently fill the mold conditioner and it was proved that the mold temperature reached $35 \pm 1{ }^{\circ} \mathrm{C}$.

In these tests, to investigate the flow lengths depending on melt temperature, injection pressure and channel depths, two or three sub values recommended by company for plastics were taken into consideration.

Before starting to measure the flow length, the melting flow index of the material was measured using a capillary rheometer. The results are given in Table 1 .

Fuzzy logic

Zadeh [11] introduced fuzzy logic for the first time in 1965. Fuzzy logic is a major development of fuzzy set theory.

Table 1 The plastic properties and operating specifications

\begin{tabular}{|c|c|c|c|c|c|}
\hline Polymers & $\begin{array}{l}\text { Specific gravity at } 23{ }^{\circ} \mathrm{C} \\
\text { and } 1 \text { atmospher }\left(\mathrm{g} / \mathrm{cm}^{3}\right)\end{array}$ & $\begin{array}{l}\text { Melt temperature } \\
\text { interval }\left({ }^{\circ} \mathrm{C}\right)\end{array}$ & $\begin{array}{l}\text { Melt flow index } \\
\text { (g/10 min) }\end{array}$ & $\begin{array}{l}\text { Pressure } \\
\text { (bar) }\end{array}$ & $\begin{array}{l}\text { Channel depth } \\
(\mathrm{mm})\end{array}$ \\
\hline $\begin{array}{l}\text { Acrylonitrile butadiene } \\
\text { styrene (ABS) }\end{array}$ & 1.05 & $180-270$ & 11 & 800 & $1.6-2-3-4$ \\
\hline Polycarbonate (PC) & 1.2 & $250-330$ & 65 & & \\
\hline Polyamide 6.6 (PA 6.6) & 1.13 & $250-310$ & 115 & & \\
\hline
\end{tabular}




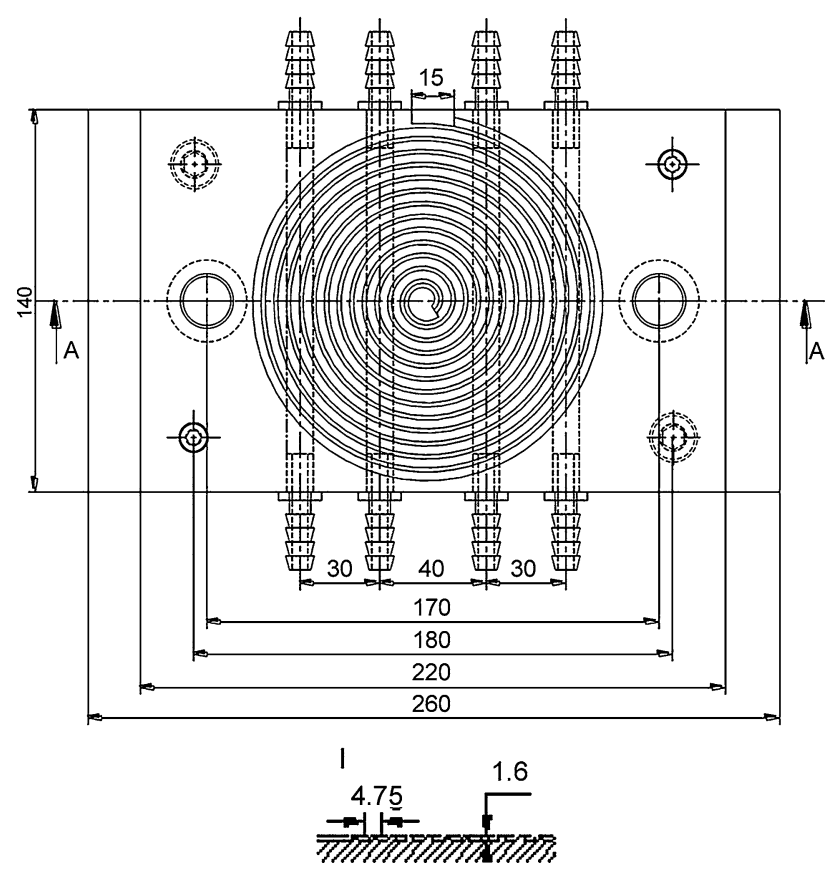

Fig. 1 Detail of plastic mold

This is a multi-valued logic that allows intermediate values to be defined between the conventional evaluations like yes/no, black/white, etc. [12]. In contrast with traditional logic theory, where binary sets have two-valued logic: true or false, fuzzy logic variables may have a true value that ranges in degree between 0 and 1. Fuzzy logic has been extended to handle the concept of partial truth, where the truth value may range between completely true and completely false. Furthermore, when linguistic variables are used, these degrees may be managed by specific functions. In other words, fuzzy logic was designed to represent and reason with knowledge in linguistic or verbal form.

As an extension of the case of multi-valued logic, valuations $\left(\mu: v_{0} \rightarrow w\right)$ of propositional variables $\left(v_{0}\right)$ into a set of membership degrees $(w)$ can be thought of as membership functions mapping predicates into fuzzy sets (or more formally, into an ordered set of fuzzy pairs, called a fuzzy relation). With these valuations, many-valued logic can be extended to allow for fuzzy premises from which graded conclusions may be drawn.

Decisions in fuzzy systems are based on inputs in the form of linguistic variables. The variables trigger, or "fire", a certain number of IF-THEN rules, which produce one or more responses (conclusions) depending on which the rules are fired. The conclusion of each rule is counterbalanced according to the degree of membership of its inputs. Usually, the centre of gravity of the responses is calculated to obtain an appropriate crisp output.
The major advantages of the fuzzy logic approach are: (1) a mathematical model is not necessary, (2) the knowledge base is formed by a set of practical rules using linguistic variables, and (3) this method is very efficient under uncertain conditions, which are common in everyday situations. According to Li and Elbestawi [13], fuzzy logic is the preferred algorithm because it is capable of providing a systematic means for dealing with the inherent uncertainties in the nonlinear processes.

\section{Fuzzification}

The purpose of fuzzification is to translate each crisp value obtained from the input into a linguistic term and grade of membership function [12, 14]. The combined linguistic term and grade membership function is also known as a fuzzy set. Several methods of fuzzification are available; however, the most common fuzzification method is the triangular method $[12,15]$. But some other methods such as Trapezoid, Gauss and etc. can also be used for fuzzy modeling.

\section{Inference system}

Malki and Umeh [15] described the inference as the brain of the fuzzy logic model. The inference element contains the rule bank (knowledge base) necessary to control the system. The rule bank is generated based on human expertise and the data obtained from the experiment (training data) [12]. The inference element employs linguistic terms resulting from the fuzzification element and the if-then statement used to decide the output of the system $[12,16]$. An if-then statement in fuzzy logic can be represented as follows [17]: IF (condition or antecedent), THEN (action or consequence)

Preconditions are present in the antecedent and a connecting operator is also required. One of the most widely used connecting operators is AND [11, 12].

\section{Defuzzification}

Output obtained by the inference element is in the form of a linguistic or symbolic value, but this form of value is not acceptable in the machine controller. Therefore, an element is required to convert the fuzzy value into a crisp value. This converting process is known as defuzzification [12, 14]. The most common defuzzification method is center-of-area [15]. The output grade membership function is also obtained along with the linguistic term conversion. A common grade membership function of the output can be obtained by multiplying the input grade membership function. The output membership function can be expressed as: 
$\mu_{\text {out }(F l)}(y)=\mu_{\text {in }(i 1)}(x) \times \mu_{\text {in }(i 2)}(x) \times \ldots \times \mu_{\text {out }(i n)}(x)$

where, $i$ is the input factor for the system. The value obtained from the degree membership function and grade of output membership function is then used in the defuzzification equation. Susanto and Chen [17] suggested the following defuzzification equation:

output $=\frac{\sum_{j=1}^{p} y_{j} \mu\left(y_{j}\right)}{\sum_{j=1}^{p} \mu\left(y_{j}\right)}$

where, $y$ is the degree of membership function of the output and $\mu\left(y_{j}\right)$ is the grade membership function of the output.

To throw light on fuzzy logic method used in MATLAB software, four test data have been used to provide four rules
$\mu(\mathrm{D} 2=1.4)=1, \mu(\mathrm{C} 2=1.6)=1, \mu(\mathrm{T} 1=224)$ $=0.4, \mu(\mathrm{T} 2=224)=0.6$

Employing Eq. (1), the degree membership function of the outputs was determined as follow:

$\mu(F l)=\mu(D) \times \mu(C) \times \mu(T)$

Rule $1: 1 \times 1 \times 0.6=0.6$

Rule 2: $1 \times 1 \times 0.4=0.4$

Rule 3: $1 \times 1 \times 0=0$

Rule 4: $1 \times 1 \times 0=0$

Then by applying Eq. (2), the defuzzified value can be calculated as Fig. 5:

Flow length $=\frac{\frac{0.6 \times 3 \times 2}{2}+(2.8 \times 0.6 \times 4.4)+(0.4 \times 0.4 \times 6)+\frac{0.2 \times 0.4 \times 6.06}{2}+(1.4 \times 0.4 \times 6.9)+\frac{(0.4 \times 0.4 \times 7.86)}{2}}{\frac{0.6 \times 3}{2}+(2.3 \times 0.6)+(0.4 \times 0.4)+\frac{(0.2 \times 0.4)}{2}+(1.4 \times 0.4)+\frac{0.4 \times 0.4}{2}}+245$

$=249.35$

to calculate the degrees of membership functions for a certain values of input data. The membership function used in this part is a triangular one as follow (Fig. 2):

$\mu_{A}(x)=\left\{\begin{array}{ll}0 & \text { if } x \leq a \\ \frac{x-a}{b-a} & \text { if } a \leq x \leq b \\ \frac{c-x}{c-b} & \text { if } b \leq x \leq c \\ 0 & \text { if } x \geq c\end{array}\right\}$

Based on the fuzzy sets of input variable in Fig. 3 and output variables in Fig. 4, the rules can be written as:

1. If (density is D2) and (channel depth is C2) and (melt temperature is $\mathrm{T} 1$ ) then (flow length is F1)

2. If (density is D2) and (channel depth is C2) and (melt temperature is $\mathrm{T} 2$ ) then (flow length is F2)

3. If (density is D2) and (channel depth is C2) and (melt temperature is T3) then (flow length is F3)

4. If (density is D2) and (channel depth is C2) and (melt temperature is T4) then (flow length is F4)

By applying Eq. (3), the degree membership functions of inputs can be calculated. If density is 1.4 and channel depth is $1.6 \mathrm{~mm}$ and melt temperature is $224{ }^{\circ} \mathrm{C}$, then the degrees of membership functions of the inputs are as follow: whereas the real value of flow length for these inputs is $249 \mathrm{~mm}$ in the test data.

Fuzzy logic modeling

In this research, to predict the flow length, MATLAB fuzzy logic toolbox was used. The fuzzy inference system predicts the amount of flow length due to the changes in injection parameters. Three parameters, including the melt temperature, channel depth and density of the materials were given to the fuzzy model as inputs and the value of flow length

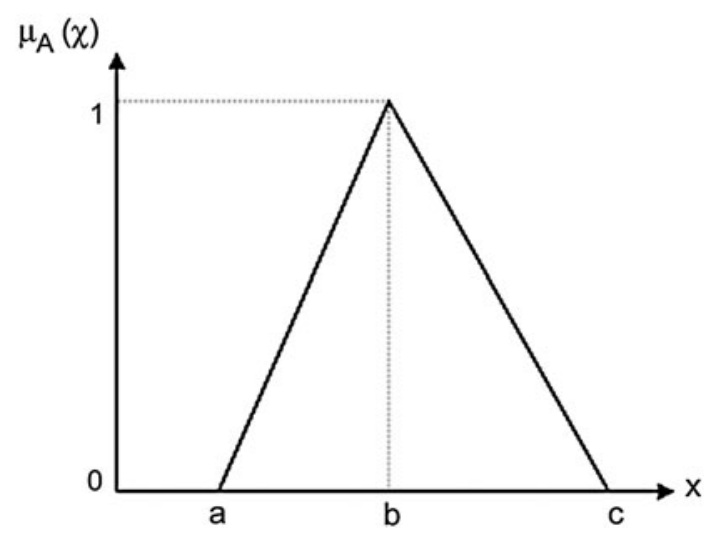

Fig. 2 Triangular membership function of the fuzzy logic method 

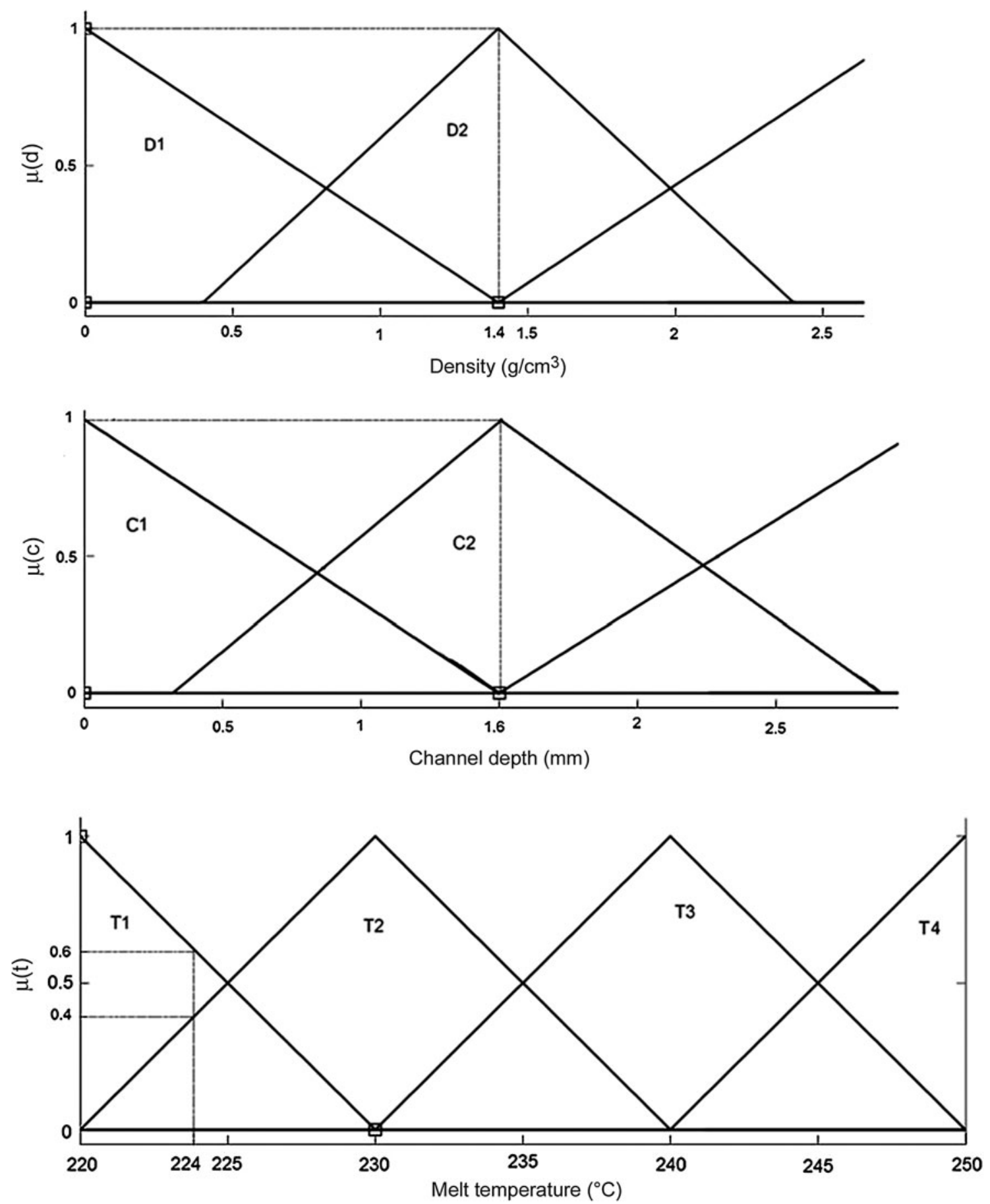

Fig. 3 Membership functions of the input variables including density, channel depth and melt temperature

was determined as the output (Fig. 6). In order to obtain an accurate result, all of the existed membership functions in MATLAB were tried and the best function was used for fuzzy modeling. In this research, Mamdani method [18] was applied to design the fuzzy logic model. In this study, difference between two sigmoidal functions (dsigmf) was the best membership function, in terms of accuracy, among the examined functions. For this reason it was used as a membership function of the model. After entering the measured data in the model, the rule base system will be designed to control the system. As it was mentioned earlier, the rule base system is designed based on the experimental data. The larger the number of experiments, the more closer the results of the experiments approximate.

In this research, the numbers of experiments conducted are 100 due to the full factorial design of experiments 


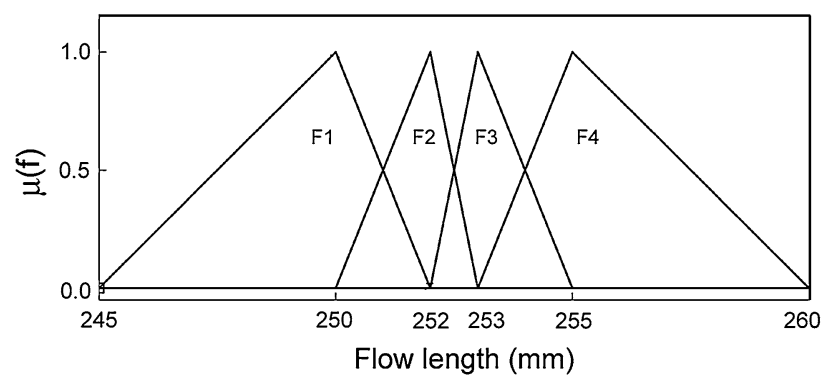

Fig. 4 Membership function of the output including the flow length

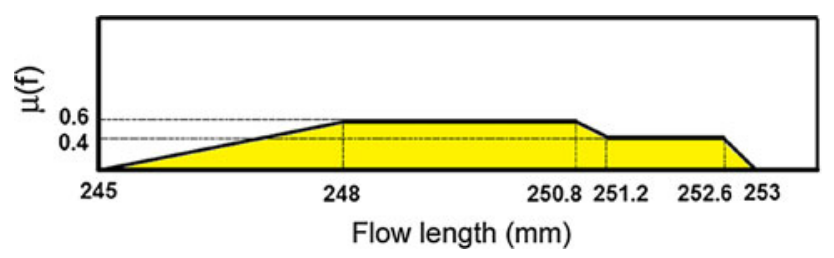

Fig. 5 Defuzzification of the variables using center-of-area ( $C o A)$ method

created by JMP software. Factorial design is widely used in cases where the determination of mutual and simultaneous effects of a number of variables on response is important [19]. Therefore, the numbers of rules must be 100 by which the input and output are connected to each other.

The fuzzy prediction system results can be shown both graphically and numerically. In Fig. 7, a part of the designed fuzzy inference system including 29 rules is given. As it is seen in Fig. 7, by entering the amounts of inputs including density, melt temperature and channel depth, in the model, the values of flow length are predicted.

Also, a three-dimensional graphic of fuzzy prediction system for ABS, PC, PA6.6 and POM plastics is shown in Fig. 8. It may be seen in Fig. 8, the values of flow length for the any amount of channel depths between 1 and $5 \mathrm{~mm}$ are graphically predictable.

In Fig. 9, another surface modeling of the fuzzy logic system is shown. In this three-dimensional graphics, the predicted values of flow length can be seen obviously in relation to the ABS, PC, PA6.6 and POM plastics and different melt temperatures. The types of plastics in this research are specified due to their densities. By increasing the melt temperature of the various plastics, the value of flow length would be increased.

In Fig. 10, the measured values of flow lengths and those obtained from the fuzzy model are compared with each other.

\section{Results and discussion}

A fuzzy logic formula was introduced for predicting the values of flow length in four plastic materials. For this propose, a full factorial design was created and appropriate experiments were conducted. The total number of experiments was 100 and carried out according to the various plastic types, melt temperature and channel depth.

It is obvious from Figs. 8 and 9 that by increasing the values of melt temperature and channel depth for any of the plastic types, there is a linear rise in flow lengths. However, the slopes of the rising in various plastics are different. For example, the variations in the flow length of the PC plastic are increased gently based on the melt temperature and channel depth where as in other plastics such as POM, the increasing rate is considerable.

In Figs. 10, 11, and 12, the measured values of the flow lengths have been compared with the estimated values obtained from fuzzy logic model. In Fig. 10, the graph has been provided for the melt temperature of less than $260{ }^{\circ} \mathrm{C}$, different channel depths and four types of plastics. In Fig. 11, the PA6.6 type of the plastic is considered and the other parameters are varied to predict the results. Finally, in Fig. 12, for investigating the effects of channel depth on the flow length, the channel depth is taken as a constant and the other inputs are varied. It is found from the graphs that the accuracy of fuzzy model is different in various materials. For example in Fig. 10, the measured and estimated values of flow length for each of the POM and ABS plastics are very close to each other whereas in cases of PC and PA6.6 materials, there is a slightly higher difference between measured and estimated values.

The largest estimated values of flow lengths by the fuzzy logic model were 1215, 596, 963 and $1040 \mathrm{~mm}$ in the order given for POM, PC, PA 6.6 and ABS.
Fig. 6 The designed fuzzy logic model for prediction of the flow length

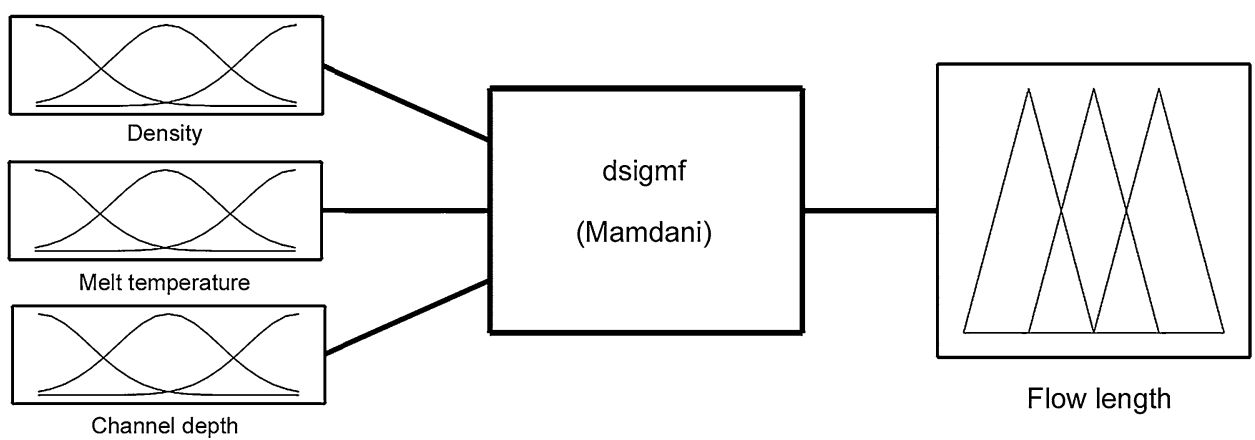




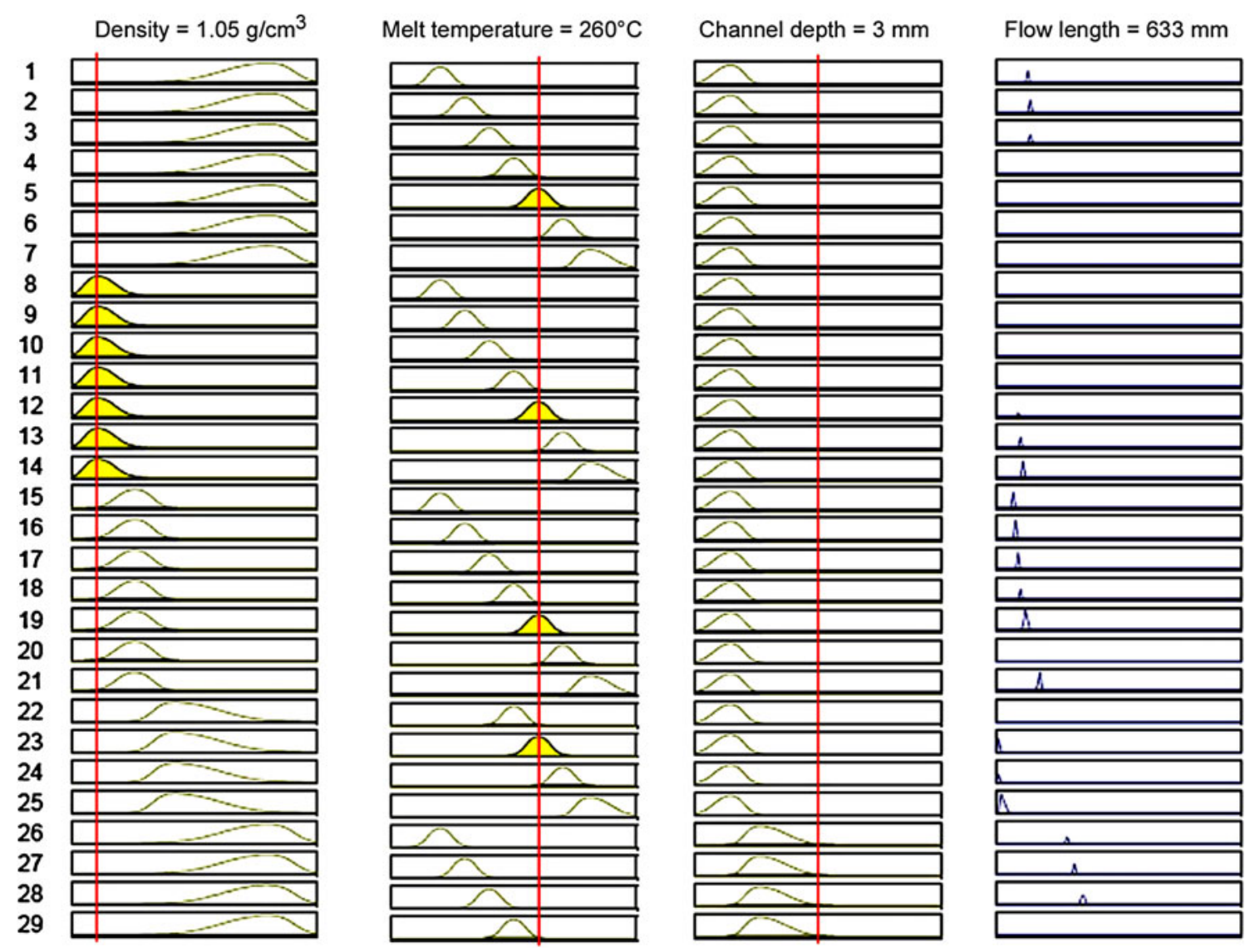

Fig. 7 The fuzzy logic inference system which is used practically to predict the flow length by entering the inputs in the system

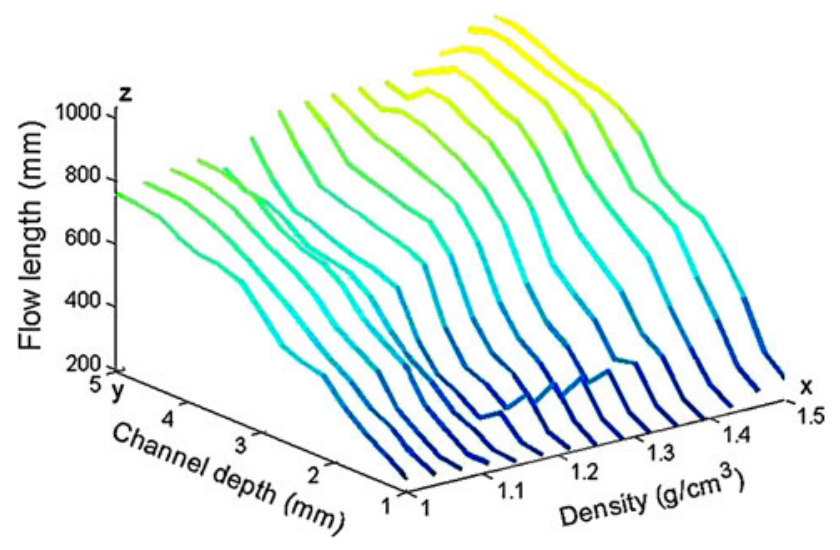

Fig. 8 Predicted amounts of flow length by fuzzy logic method in relation to the density and channel depth

In general, the accuracy of fuzzy logic prediction system is acceptable and it can be used practically in injection molding and mold designing process. The accuracy of the fuzzy logic is relatively less than the neural network method which has been applied by Karataş et al. [2], for a small number of data fuzzy logic is more accurate than the neural network. It is confirmed by Fig. 13 that the amount

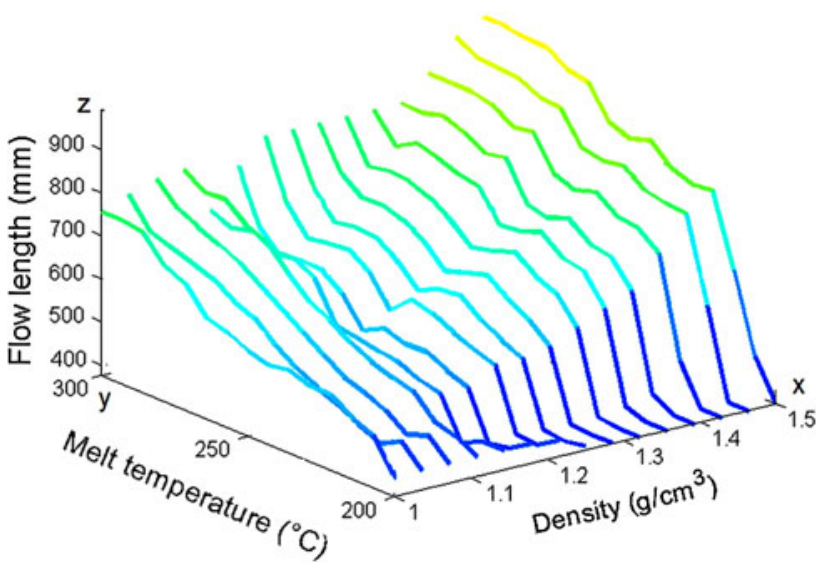

Fig. 9 Predicted amounts of flow length by fuzzy logic method in relation to the density and melt temperature

of $R^{2}$ for the measured and estimated values is 0.920529 . Again in Fig. 13, the measured and estimated values of flow lengths were compared to each other for all of the observations. The prediction of the flow length, both in numerical and graphical forms is one of the specifications of the fuzzy model in this research. 


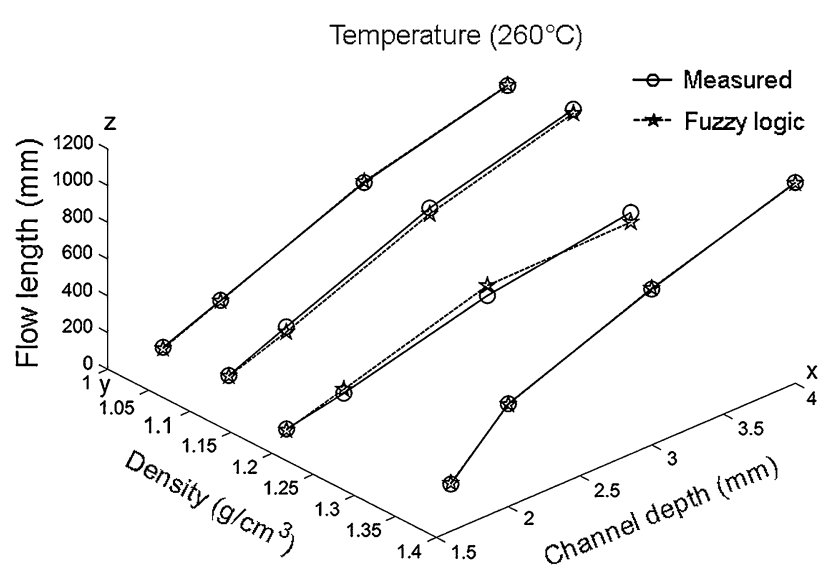

Fig. 10 Comparison of the measured and predicted flow lengths by fuzzy logic method in relation to different densities and channel depths in temperature of $260{ }^{\circ} \mathrm{C}$

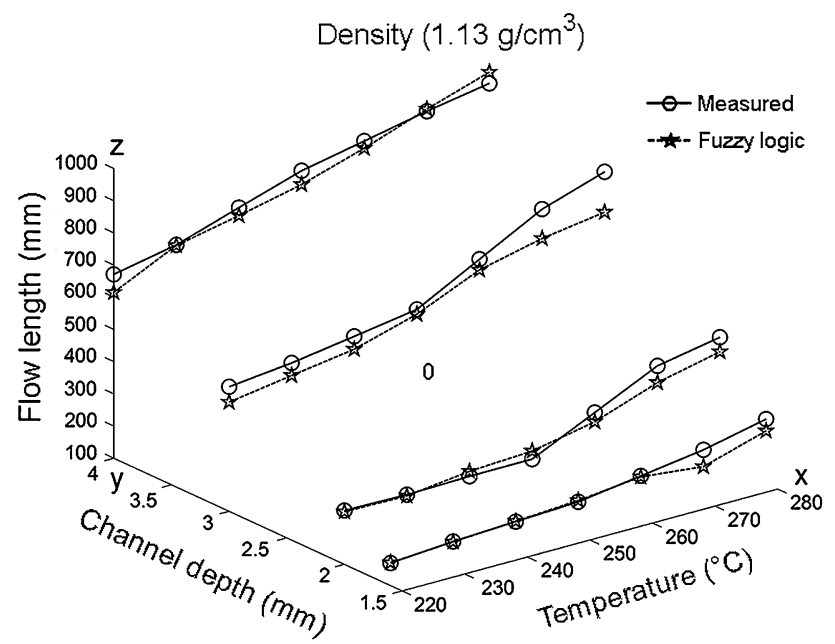

Fig. 11 Comparison of the measured and predicted flow lengths by fuzzy logic method in relation to the different channel depths and melt temperatures in density of $1.13 \mathrm{~g} / \mathrm{cm}^{3}$

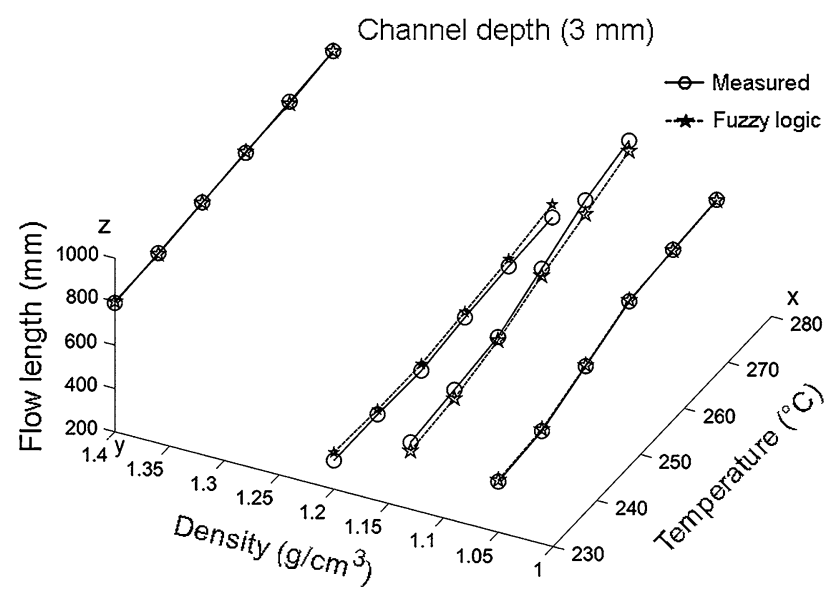

Fig. 12 Comparison of the measured and predicted flow lengths by fuzzy logic method in relation to different melt temperatures and densities in channel depth of $3 \mathrm{~mm}$

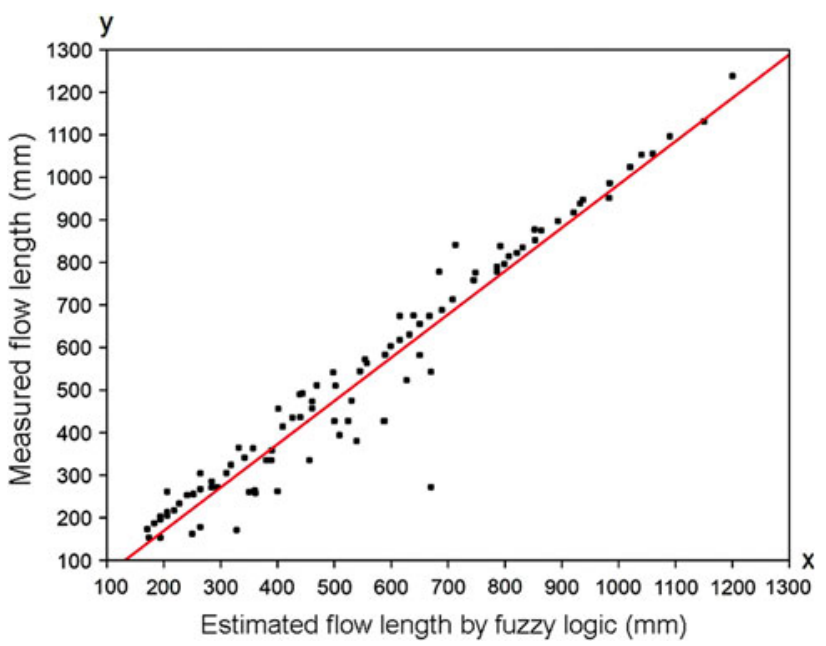

Fig. 13 Comparison of measured and predicted flow length by fuzzy logic method

\section{Conclusion}

The results of this research show that the fuzzy logic system is a reliable method to predict the values of flow length to prevent any short shot before an injection process. Even though there are some differences between the measured and estimated values, yet by conducting a small number of tests, fuzzy logic can appropriately approximate the results. Also it is found from the results that the fuzzy logic can predict accurate results when the used plastics have close specifications with one another. By using fuzzy logic to predict the amounts of flow length in this research, prediction is possible for non-skilled operators, because there is no need of any other technical software such as moldflow. Before injection process, the input values are entered in the fuzzy system by the operator and the flow lengths will estimated accurately. The prediction system can be applied and generalized for more polymer types and various inputs. By conducting more experiments, the prediction will be more accurate and reliable. From the results of the research, it is concluded that the fuzzy logic system can be applied to the other tasks in injection molding process. For example, it is used to predict the warpage in injection molding.

Acknowledgments The work was supported by Çalışkan Plastic Ltd. Şti. The supports are gratefully acknowledged.

Open Access This article is distributed under the terms of the Creative Commons Attribution License which permits any use, distribution, and reproduction in any medium, provided the original author(s) and the source are credited.

\section{References}

1. Ergüney S, Karataş Ç, Sarıtaş S (2005) Investigation of mouldability of commercial plastics. J Fac Eng Arch Gazi Univ (Turkish) 20:297-303 
2. Karataş Ç, Sözen A, Arcaklioğlu E, Ergüney S (2007) Modelling of flow length in the mould of commercial plastics using artificial neural networks. Mater Design 28:278-286

3. Farshi B, Gheshmi S, Miandoabchi E (2011) Optimization of injection moulding process parameters using sequential simplex algorithm. Mater Design 32:414-423

4. Hua T, Krishna MP (2010) Numerical simulation of reactive flow in liquid composite moulding using flux-corrected transport (FCT) based finite element/control volume (FE/CV) method. Int J Heat Mass Trans 53:2256-2271

5. Xuanping W, Xikui L (2010) Numerical simulation of three dimensional non-Newtonian free surface flows in injection moulding using ALE finite element method. Finite Elem Anal Des 46:551-562

6. Mallakpour S, Dinari M (2011) High performance polymers in ionic liquid: a review on prospects for green polymer chemistry. Part II: polyimides and polyesters. Iran Polym J 20:259-279

7. Zema L, Loreti G, Melocchi A, Maroni A, Gazzaniga A (2012) Injection moulding and its application to drug delivery. J Control Release 159:324-331

8. Tsai KM, Hsieh CY, Lo WC (2009) A study of the effects of process parameters for injection moulding on surface quality of optical lenses. J Mater Proc Technol 209:3469-3477

9. Karrabi M, Ghoreishy MHR, Bakhshandeh G (2004) Rheological study of tyre tread compound. Part I: determination of wall slip coefficient and elastic swell using capillary rheometer. Iran Polym J 13:317-325
10. Wu HW, Xu HH, Qu JP, Zhang SD (2006) Cavity pressure response and melt flow length during dynamic injection moulding. Polym-Plast Technol Eng 45:935-937

11. Zadeh LA (1965) Fuzzy sets. Inform Control 8:338-353

12. Azadeghan A, Porobic L, Ghazinoory S, Samouei P, Kheirkhah AS (2011) Fuzzy logic in manufacturing: a review of literature and a specialized application. Int J Prod Econ 132:258-270

13. Li S, Elbestawi MA (1996) Tool condition monitoring in machining by fuzzy neural networks. J Dyn Syst-T ASME 118:665-672

14. Zeeshan M, Moataz AA (2010) Software development effort prediction: a study on the factors impacting the accuracy of fuzzy logic systems. Inform Software Tech 52:92-109

15. Malki HA, Umeh CG (2000) Design of a fuzzy logic based level controller. J Eng Technol 17:32-38

16. Hakki OU, Greg W (2009) A fuzzy quality control-decision support system for improving operational reliability of liquid transfer operations in laboratory automation. Expert Syst Appl 36:8064-8070

17. Susanto V, Chen JC (2003) Fuzzy logic based in-process toolwear monitoring system in face milling operations. Int $\mathbf{J}$ Adv Manuf Technol 21:186-192

18. Fuzzy logic toolbax ${ }^{\mathrm{TM}}$ Users Guide (2011) The Math Works. Natick, MA, US

19. Tavanai H, Hamadani AZ, Askari M (2006) Modelling of colour yield for selected reactive dyes in dyeing cotton cloth by two phase pad-steam method. Iran Polym J 15:207-217 